Int. J. Electrochem. Sci., 15 (2020) 3479 - 3494

International Journal of

ELECTROCHEMICAL

SCIENCE

WWW.electrochemsci.org

\title{
Porous Si@C Composite Anode Material Prepared Using Dopamine as a Carbon Source for High-Performance Lithium- Ion Batteries
}

\author{
Shibin Liu ${ }^{l}$, Xiangcai Meng ${ }^{1}$, Jianwei Xu ${ }^{l}$, Hongyu Zhou ${ }^{1}$,Shibin Liu ${ }^{1, *}$ and Jing Wang ${ }^{2, *}$ \\ ${ }^{1}$ School of Materials Science and Engineering, Jiamusi University, Jiamusi 154007, China \\ ${ }^{2}$ School of Materials Science and Engineering, Baise University, Baise 533000, China \\ *E-mail: christainvieri@126.com (SB L) jmsdxwangjing@163.com (J W)
}

doi: $10.20964 / 2020.04 .52$

Received: 26 December 2019 / Accepted: 4 February 2020 / Published: 10 March 2020

Porous silicon-carbon ( $\mathrm{Si} @ \mathrm{C})$ composites as anode materials for Li-ion batteries are considered to be the most effective material for solving the problem of poor cycling performance of conventional silicon anode materials. However, the preparation process is complex and there are still some defects and shortcomings from the carbon source that limit its further application. Herein, we demonstrate a method through the self-polymerization of dopamine to produce Si@C composite anode materials with core-shell structures. The preparation process is simple, and the raw materials are environmentally friendly and do not cause pollution. The experimental results show that the material has good cycling stability, rate capability and an initial Coulombic efficiency of $87.7 \%$. This provides a new idea for the application of Si@C composite anode materials.

Keywords: Li-ion battery,Porous Si,Carbon coating,electrochemical properties.

\section{$\underline{\text { FULL TEXT }}$}

(C) 2020 The Authors. Published by ESG (www.electrochemsci.org). This article is an open access article distributed under the terms and conditions of the Creative Commons Attribution license (http://creativecommons.org/licenses/by/4.0/). 